\title{
UNA POÉTICA DE LA INCERTIDUMBRE: PROCEDIMIENTOS EROSIVOS EN TRES OBRAS DE ELENA GARRO
}

Las obras de Elena Garro abundan en múltiples aproximaciones a lo incierto. Si bien por su propia condición esto podría presentarse como un aspecto inasible, Garro parece ensayar acercamientos que apuntan, al mismo tiempo, a representar la incertidumbre y a inscribirla como un rasgo de mayor alcance: la constituye como un aspecto esencial de su poética. Hay un trabajo literario, coherente y sostenido que Garro despliega por medio de una serie de procedimientos erosivos, de cuya articulación resulta un efecto de lectura que produce extrañamiento en el lector.

En este trabajo, me propongo revisar tres obras en las que Garro vuelve sobre temas afines y despliega diversas estrategias literarias: Testimonios sobre Mariana ${ }^{1}$, Reencuentro de personajes ${ }^{2}$ y Memorias de España $1937(1992)^{3}$. Por medio de la difusión de las voces, del desdibujamiento de la anécdota y de la creación concienzuda de la confusión y el entredicho, estas obras ofrecen un rico terreno para la exploración de procedimientos de erosiones y nuevas construcciones en las que se desvirtúa intencionalmente el supuesto material "original”.

Si bien estos procedimientos no son una novedad en el ámbito de la literatura cuando Garro los pone en práctica ni se trata de un rasgo exclusivo de su poética, la singularidad reside en la forma en que los adopta y en el uso que les $\mathrm{da}^{4}$. Tratándose de una autora que, en espe-

1 Grijalbo, México, 1981.

2 Grijalbo, México, 1982.

3 Sigo la edición de Siglo XXI, Barcelona, 2011.

${ }^{4}$ Es imprescindible reparar en la función ulterior que desempeñan estos procedimientos, que ya habían sido usados con anterioridad. En el repertorio estilístico de las vanguardias literarias, por mencionar un ejemplo, ya se encuentran algunos de estos procedimientos. Es de notar, como explica Jorge SCHWARTz en la "Introducción" a Las vanguardias latinoamericanas. Textos programáticos y críticos (F.C.E., México, 1991), que el afán, en este caso, tenía objetivos distintivos: la utopía de transformación, en la forma de una reacción política de negación del pasado (p. 42), podría inscribirse como una función pragmática en el ámbito social (p. 41). 
cial en su producción tardía -a la que pertenecen las obras que propongo analizar-, se vale del material biográfico para elaborar una compleja imagen de sí misma ${ }^{5}$, estos procedimientos forman parte intrínseca del tratamiento de los acontecimientos biográficos, en contra de la divulgada noción de que la autora utilizaba sus ficciones como espacios para llevar a cabo "ajustes de cuentas". En este sentido, no hay trasposición directa de la anécdota y es en ello en lo que nos interesa reparar. En el caso de Garro, los procedimientos que analizamos aquí no responden exclusivamente a una función estética, sino que el resultado estético obedece a un concienzudo uso literario de las anécdotas biográficas como material de trabajo autoral, en términos formalistas.

La relación de estas obras tardías -o de publicación tardía- con algunos aspectos de la vida de Garro es muy estrecha. Cronológicamente, Memorias recupera el episodio del viaje de Garro, recién casada con Octavio Paz, al "Segundo congreso internacional de escritores antifascistas" que tuvo lugar en España en 1937. Publicado muchos años después, su escritura es de difícil ubicación: por un lado, Garro afirma haber escrito algunas notas mucho antes de su publicación ${ }^{6}$, pero el tono y el punto de vista son mucho más afines a su escritura posterior. Hay que tener en cuenta que entre los sucesos narrados y la publicación transcurren alrededor de cincuenta y cinco años. Las dos novelas, por otro lado, y en especial Testimonios, utilizan material correspondiente a la estadía de la autora y de su familia en Europa, que comienza a mediados de la década de los cuarenta y concluye los primeros años de la década siguiente, con una duración de alrededor de cinco años. Esta información fáctica es imprescindible para la concepción de las obras, aunque su relación con las ficciones que analizamos escapa al interés de este artículo ${ }^{7}$; sólo volveremos brevemente cuando se mencionen las referencias sobre el uso de la roman à clef en el caso de Testimonios.

Testimonios sobre Mariana es una novela conformada por tres testimonios de desigual extensión que, enunciados por Vicente, Gabrielle y André, responden cuando se les pregunta por Mariana y, en esas extensas respuestas, dan cuenta de la vida del personaje en cuestión, de su marido Augusto y de un enjambre de personajes que pululan alrededor de la pareja central en el París de posguerra. Es importante seña-

5 Sobre este punto, véase Lucía Melgar y Gabriela Mora, Elena Garro: lectura múltiple de una personalidad compleja, Benemérita Universidad Autónoma de Puebla, Puebla, 2002.

${ }^{6}$ Véase Patricia Rosas Lopátegui, "Prólogo: sobre una saga memorable”, en Memorias de España 1937, Siglo XXI, Barcelona, 2011, pp. 5-18.

7 Para un análisis de esta relación, véase SAndra Messinger Cypess, Uncivil wars. Elena Garro, Octavio Paz, and the battle for cultural memory, University of Texas Press, Austin, 2012, en especial el capítulo "Love and war don't mix: Garro and Paz in the Spanish Civil War", dedicado enteramente a este viaje y a las obras de Garro y Paz que se relacionan con él. 
lar que los tres testimonios difieren entre sí en aquello de lo que dan cuenta, en el nivel de la anécdota, pero estas diferencias son difíciles de rastrear y precisar, porque los relatos no versan sobre las mismas acciones concretas todo el tiempo, sino que divagan un poco, dejando a la vista más sus propias impresiones sobre la hostil relación que Augusto y Mariana mantienen (donde abunda la descripción de cómo él la maltrata y ella carece de medios para huir con su hija ${ }^{8}$, que en cosas concretas de la historia del grupo. Cabe destacar que las lecturas críticas señalan la abundante presencia de datos autobiográficos reconocibles en esta novela que invitan a considerar la relación entre Mariana y Garro, Augusto y Octavio Paz, entre otras identidades posibles ${ }^{9}$.

Reencuentro de personajes es una novela que versa sobre un acotado segmento de la vida de Verónica, en el que ella, en compañía de Frank, viaja por varios hoteles de Europa en un incomprensible periplo -o "loco correr" (Reencuentro, p. 35)-que acaba en París. Allí, rodeados de una serie de curiosos personajes, continúan inmersos en una repetida dinámica de humillación y maltrato de Frank hacia Verónica, quien se siente incapaz de escapar por la falta de dinero y por no tener permiso de trabajo en un país que no es el suyo. Poco a poco va develándose una historia criminal que involucra a Frank y a la pandilla de personajes con quienes se relacionan. El final sugiere la lectura de dos novelas que varias veces se repiten en el libro: Tender is the night ${ }^{10}$ y Brideshead revisited ${ }^{11}$. La crítica también señala la posible lectura de esta novela en clave donde la pareja central evocaría a Garro y a Paz ${ }^{12}$.

Memorias de España 1937 se presenta como un libro autobiográfico en el que Garro repasa el viaje que emprendió ese año para acompañar a Paz al encuentro de escritores antifascistas en España. Escrito en primera persona, el libro relata los desplazamientos de la pareja por varias ciudades de España, París y su regreso a México. Asimismo, el relato abunda en descripciones y anécdotas del paisaje humano que

${ }^{8}$ He aquí un fragmento que ilustra esta relación: "En presencia de la muchacha se discutía su educación, sus tendencias autodestructivas, su frigidez sexual, su lesbianismo latente, su rechazo a la sociedad y su esquizofrenia, su falta de responsabilidad que la imposibilitaba para educar a su hija" (p. 140).

${ }^{9}$ RHInA Toruño simplifica al extremo la cifra de esta roman à clef en simples identidades: "En la novela Testimonios sobre Mariana (1981), la cual es autobiográfica, aparece Bioy con el nombre de Vicente y Silvina, como Sabina, Pepe Bianco como Pepe, Octavio Paz como Augusto" (Cita con la memoria: Elena Garro cuenta su vida a Rhina Toruño, Prueba de Galera, Buenos Aires, 2004, p. 33).

10 Francis Scott Fitzgerald, Tender is the night [1934], Harper Press, London, 2011.

11 Evelyn Waugh, Brideshead revisited. The sacred and profane memories of Captain Charles Ryder [1945], Little Brown \& Co., Boston, 1946.

12 Véase Julie Jones, "No Man's Land: Reencuentro de personajes", en A common place: The representation of Paris in Spanish American fiction, Bucknell University Press, Lewisburg, 1998, pp. 93-110, donde se discute este tema in extenso. 
rodeaba a la pareja en este episodio de su vida, muchos de sus personajes son personas públicas reconocidas.

Un factor evidente que se encuentra en las tres obras es la tematización de episodios de la vida privada como material literario y éste puede ser analizado desde varios puntos de vista. Desde el trasvase directo a la concepción de la literatura como única herramienta para librar algunos de sus combates matrimoniales, la simplificación de esta relación por parte de algunos críticos ha provocado una minimización del trabajo literario que Garro demuestra en sus novelas ${ }^{13}$. En el otro extremo de las concepciones críticas, están las que reparan en la escritura como objeto central de la lectura. De este lado, Kristine Ibsen retoma la dicotomía entre lo público y lo privado para detenerse en la intersección de la escritura con la condición femenina y cómo en ésta el efecto de intersección imprime una singularidad especial al trabajo literario de Garro. Su artículo sobre Testimonios comienza de la siguiente manera:

In societies where the female subject has traditionally been more closely affiliated with the private, rather than the public, sphere, the act of writing itself may suggest a transgression of authority. The integration of autobiographical elements in female-authored texts violates cultural boundaries twice over: not merely by writing, but by making public details of a private life ${ }^{14}$.

13 Para un amplio abanico de acercamientos, véanse M.H. Jastrzembski, From metaphor to symbol: Otherness in "Testimonios sobre Mariana", tesis; M.A. Umanzor, La visión de la mujer en la obra de Elena Garro: "El árbol", "Los perros", "Los recuerdos del porvenir", “Testimonios sobre Mariana” y "La casa junto al río”, Eds. Universal, Miami, 1996; de P. Rosas Lopátegui, El asesinato de Elena Garro: Periodismo a través de una perspectiva biográfica, Porrúa, México, 2005; "Prólogo: sobre una saga memorable”, en E. Garro, Memorias de España 1937, Siglo XXI, Barcelona, 2011, pp. 5-18; Testimonios sobre Elena Garro: Biografía exclusiva y autorizada de Elena Garro, Eds. Castillo, Monterrey, 2002; "Testimonios sobre Mariana” de Elena Garro: Un acercamiento psicoanalítico, tesis; Yo sólo soy memoria: Biografía visual de Elena Garro, Eds. Castillo, Monterrey, 2002; y D. Galván, "Feminism in Elena Garro's recent works", en A different reality: Studies on the work of Elena Garro, ed. A.K. Stoll, Bucknell University Press, Lewisburg, 1990, pp. 136-146. Consabido es que abundan lecturas que se deslizan sin solución ni continuidad entre el plano temático de la obra y la biografía. Un ejemplo, que ofrece una de las claves para comprender esta tendencia (la creación de una imagen de sí misma de parte de la propia Garro a la que numerosos críticos han sido ciegamente obedientes) es la de Toruño (con su singularísima sintaxis): "Elena Garro, como era su costumbre de recurrir a lo autobiográfico al escribir sus novelas, «para saldar cuentas» como ella lo decía o «para que el mundo sepa la verdad», otra expresión favorita de ella, que tengo varias veces grabadas en mis entrevistas con Elena” (p. 39). Por el contrario, sugerente es la lúcida imagen fluvial por medio de la cual LuzELENA GutiérRez DE Velasco explica que escapar a los análisis que "privilegian el mito, lo biográfico o la poeticidad" en la obra de Garro es "bogar a contracorriente" (reseña al libro de Margarita León, La memoria del tiempo: la experiencia del tiempo y del espacio en "Los recuerdos del porvenir" de Elena Garro, NRFH, 54, 2006, p. 262).

14 "Self-representation, silence, and the discourse of madness in Testimonios sobre Mariana”, Confluencia, Greeley, 1999, núm. 2, p. 93. 
Esta transgresión, en el caso de Garro, no tiene exclusivamente que ver con la exhibición de fragmentos de su vida privada, sino con un trabajo altamente marcado por las estrategias literarias de erosión y borrado que conllevan al extrañamiento y a la incertidumbre, como veremos más adelante. Daniel Balderston, en su reseña de la novela, apuntaba ciertamente al recurso de la anécdota literaria (resorte, quizá, de la roman à clef) como estrategia que resume su éxito en lo inasible de la persona real, en su supuesto borramiento:

Entre el chisme y la anécdota literaria existe una diferencia fundamental: el chisme se usa para atacar a una persona real (aunque al atacarla soslayadamente se le hace difícil toda defensa), mientras que la anécdota se cuenta de una persona imaginaria (que de todos modos no podría defenderse). Al utilizar el chisme como técnica literaria se combinan dos virtudes antitéticas: se calumnia a una persona real al representarla en el texto literario, pero se le priva de toda manera de defenderse al declarar que sólo se trata de una persona imaginaria ${ }^{15}$.

De este modo, el "uso del chisme como técnica literaria" resulta en la combinación del material biográfico o histórico con un deliberado trabajo escriturario sobre esta materia prima. Nos concentraremos aquí en los detalles de este deliberado trabajo, pues uno de sus principales efectos de lectura es la ambigüedad. A propósito de Testimonios, Magdalena Maíz insiste, asimismo, en la ambigüedad:

Historia y ficción, imaginación y certeza, especulación y realidad tejen su inscripción en la ambigüedad de un texto que se autodenomina novela de tono autobiográfico. Crónica personal quizás, memoria ficticia o testimonio novelado que se autodefine a sí mismo precisamente en el juego dialéctico de su escritura y de su lectura ${ }^{16}$.

El uso del material autobiográfico es entonces recurrente en estas tres obras. Los procedimientos de los que se vale, tanto en las dos primeras obras, abiertamente ficcionales, como en la tercera, autobiográfica o de intención testimonial, le permiten deslizarse hacia una escritura donde las identidades se desdibujan, pierden sus contornos definidos y prima la ambigüedad y sólo por medio de una actitud de lectura respetuosa de esta singularidad, que consiste en privarse de la tentación de cancelarla, se preservan las posibilidades interpretativas que Garro logra con su arduo trabajo literario.

15 Daniel Balderston, "Elena Garro. Testimonios sobre Mariana”, Hispam, 1983, núm. 36, p. 115.

16 Magdalena Maíz, "Elena Garro: Testimonios sobre Mariana", Chasqui: Revista de Literatura Latinoamericana, Tempe, 11 (1982), núms. 2/3, p. 75, nótese cómo está matizada la cuestión de la memoria y del testimonio en esta cita. 
Testimonios y Reencuentro fueron publicadas en años sucesivos a principios de la década de los años ochenta y tienen varios puntos en común: en ambas novelas proliferan los personajes en formaciones gregarias, las acciones se centran principalmente en lo que se dice (más que en lo que se hace), transcurren mayormente en París (con algunas escapadas, distintas en cada caso), tienen un personaje femenino central -Mariana, Verónica- que aparentemente libra una especie de batalla personal contra lo que la rodea y no dispone de medios económicos ni legales, es decir, no dispone de ninguna moneda social ni políticamente consensuada para valerse por sí misma ${ }^{17}$. Memorias también tiene una protagonista principal, "Elena Garro", que también está rodeada de un enjambre de personajes, y la construcción de la identidad tiene puntos de contacto con las novelas de la década anterior. Baste señalar estos encuentros para justificar la posibilidad -y en especial la productividad-del diálogo entre ellas. No obstante, es en las sutiles diferencias o singularidades de cada obra en las que queremos detenernos aquí, para luego reconocer la tendencia análoga que se desprende de estos procedimientos, así como sus consecuencias estéticas e ideológicas.

\section{TESTIMONIOS SOBRE MARIANA}

Mariana, personaje central de Testimonios, es un ser inasible sobre el que se dicen muchas cosas, pero cuya voz, opinión y sentir están ausentes y sólo pueden inferirse equívocamente. Este equívoco está alimentado por el hecho de que las inferencias siempre estarán contaminadas por los enunciadores de los testimonios, por su relación con Mariana y por nuestra percepción de su punto de vista. Como lectores, sabemos de Mariana lo que los personajes estrechamente relacionados con ella quieren hacernos saber: es una información filtrada tanto por sus opiniones como por sus construidas intenciones ${ }^{18}$. En este sentido, es importante delinear tres niveles de representación que se establecen en torno a Mariana. En primer lugar, tenemos los testimonios: en ellos, cada

17 Aquí resuenan los ecos de la reflexión de Kristine IbSEn acerca de los ámbitos privados y públicos, asumidos como temas encarnados en los personajes.

18 Nótese que esta lectura se opone diametralmente a otras, como la de M.A. UMANZOR, op. cit., p. 106, quien no encuentra ningún problema epistemológico al afirmar: "Son cuatros [sic] narradores los que desarrollan el relato: Vicente, André, Gabrielle y Elena Garro como autora”. Por el contrario, nos inclinamos más en consonancia con Ibsen, quien resume la existencia del personaje de este modo: "In short, Mariana exists only as a verbal creation of others, and this creation itself is shaded by memory; or as Taylor observes, she is «the memory of a memory»". En esta misma línea, BALDERSTON hace hincapié en el juego deliberado que se opera en la novela, y afirma que "el misterio es el de su propia vida que ha decidido no contarnos mientras nos la cuenta. Habla de sí misma sin revelarse, revela que no se nos revela casi nada" (p. 94). 
una de las primeras personas filtran sus recuerdos y los elaboran para componer tres imágenes desiguales de Mariana. En segundo lugar, están las voces, de las cuales los que testimonian se hacen eco; así, percibimos en un segundo grado de representación las voces de Augusto, Pepe, Bertrand y muchos más personajes que se manifiestan sobre el personaje central, y sus dichos están reproducidos dentro del marco de los testimonios del primer nivel. En tercer lugar, y quizá el más difícil de notar por el carácter puntual y menos esparcido dentro de la novela, son tres materiales escritos que se indican en la novela y que versarían -ya que no son ofrecidos al lector, sino solamente mencionados-sobre Mariana como tema. Los tres escritos son una novela que Boris escribió sobre Mariana; la novela que Gabrielle, paralelamente con su relato, está escribiendo también sobre ella, y un diario que Mariana supuestamente ha dejado. Este último nivel, que abisma la escritura dentro de la escritura, es el más inquietante. Mariana despierta la escritura, la provoca como objeto de su predicación, pero esos escritos son escamoteados -que no completamente escondidos-al lector, quien sabe de su existencia, pero no de su contenido. Considero que estos tres niveles, legibles en la novela, acentúan la relatividad de los testimonios, enfatizándola en su proliferación. Al potenciar los niveles de representación, se magnifica la idea de que la coexistencia de los tres testimonios debilita simultáneamente la fiabilidad de todos ellos ${ }^{19}$.

Es notable el juego entre la aparente fiabilidad que inspira una palabra como "testimonio" con los procesos erosivos puestos en marcha en la novela. En este sentido, son iluminadoras las reflexiones de Diana Amador ${ }^{20}$ y de Julie Winkler ${ }^{21}$, quienes, cada una desde su pun-

19 Volvemos a encontrarnos en las antípodas de interpretaciones como las de M.A. UMAnzor que hacen de las lecturas críticas de estas obras de Garro una especie de cruzada personal de la defensa del género, actitud que le permite manifestarse en términos absolutamente extraliterarios: "nuestra meta será única y exclusivamente hacer resaltar la credibilidad de las evidencias aportadas por los amigos del matrimonio. En esta forma se desacredita el discurso hegemónico masculino representado por Augusto por las afirmaciones de seres de su mismo sexo y reafirmadas por la misma autora y Gabrielle” (op. cit., p. 103, las cursivas son mías). Si hay algo debilitado en la novela, no es otra cosa que la credibilidad, absolutamente carente de cualquier tipo de "evidencia" extralingüística. El peligro de este tipo de lecturas es que el desliz hacia una de corte estrictamente biográfico es casi inevitable; esto puede notarse en esta desafortunada afirmación de M.H. JAstrzEMBsKi, de la que queda omitido o desestimado el trabajo específicamente literario: "Testimonios is autobiographical in nature, and thus a virulent criticism of Octavio Paz's treatment of Garro" (op. cit., p. 3).

20 "Elena Garro y las perspectivas de la memoria. Relato fotográfico de una vida equívoca”, en Elena Garro. Recuerdo y porvenir de una escritura, eds. L.E. Gutiérrez de Velasco y G. Prado, Tecnológico de Monterrey-Universidad Iberoamericana-Fondo Nacional para la Cultura y las Artes, Toluca, 2006, pp. 43-57.

21 Light into shadow: Marginality and alienation in the work of Elena Garro, Peter Lang, New York, 2001. 
to de vista, reparan en lo equívoco y confuso de este uso del material ficticio que se pretende testimonial. Amador afirma que "los testimonios son tan variados e inconsistentes que difícilmente es posible asegurar una versión y el lector tendrá que sobrevivir a la perenne sensación de extravío e incertidumbre que la autora sostiene a lo largo de este relato fotográfico de una vida equívoca" (p. 44). Winkler, por su parte, destaca el contraste entre las expectativas que despierta el género testimonial y lo que la novela ofrece en realidad:

Although the term "testimony" brings to mind official statements, supported by facts, and also suggests the strict adherence to truth required by testimony given in a court of law, nothing could be further from the case in this novel. In fact, by the end the reader is left with a hodgepodge of impressions, contradictions, innuendoes, and opinions so jumbled that no clear picture ever emerges of Mariana (p. 137).

Hay algunos otros rasgos que vale la pena señalar, porque contribuyen también a crear una atmósfera incierta. En primer lugar, si nos detenemos en algunas descripciones de Mariana, podemos notar el carácter eminentemente críptico de su formulación. Así, Vicente dice: "Me inquietaba Mariana; era como una flecha que indica: «Peligro» pero quise ignorarlo" (p. 17). Y un poco más adelante: "Mariana tenía algo tan saludable que resultaba enfermizo y peligroso. La miré con fijeza y envidié su valor para entregarse a la nada" (p. 23). Y un poco después: "Decir que nos comunicábamos por una corriente secreta no es decir nada y sin embargo así nos sucedía” (p. 60). Estos comentarios de Vicente dan el tono de muchas descripciones posteriores no sólo en su testimonio, sino también en los otros dos. Como se ve en estos fragmentos, la voz que narra está consciente de esta vaporosa aproximación a Mariana y sus palabras dan explícita cuenta de este constante matiz.

Como efecto contiguo del procedimiento recién descrito, puede notarse la distancia que los narradores reconocen que los separa de Mariana. En el testimonio de Vicente, se lee: "Ocupaba un lugar que no compartía con nadie, establecía una barrera entre ella y los demás, se colocaba para siempre en el equívoco, mientras que yo continuaba ocupando mi sitio" (p. 67). De manera similar, en el de Gabrielle se lee:

Me sorprendió que estuviera dispuesta a hablar. Levantó los hombros con desdén y volvió a mirar las copas de los árboles. Su problema era que nunca hablaba de lo que le ocurría. Estaba amurallada y si alguien intentaba hacerla hablar o se reía o decía impertinencias. Ocultaba una verdad que quizá ni ante ella misma quería confesar. Quise penetrar en el misterio que la envolvía (p. 156).

Estos ejemplos ilustran cómo se sugiere que existe una estrecha relación entre la incomprensibilidad de Mariana y su actitud o posición 
distante con respecto a los narradores (aunque pueda hacerse extensiva también, en la mayoría de los casos, a otros personajes o a la gente en general). La distancia se traduce así en otro elemento que cuestiona la fiabilidad de los testimonios; asumida, pero al mismo tiempo denunciada, debilita los cimientos sobre los que denodadamente se proponen dar una imagen cabal y única de Mariana. Dentro de esta difusa construcción del personaje, se inscribirían también muchas de las referencias que la describen negativamente y que nos llegan filtradas por estas voces distantes ${ }^{22}$.

A propósito de estos dos aspectos -descripciones marcadamente crípticas y distancia estructural-, cabría señalar, por último, el énfasis que las voces narrativas ponen acerca de una cierta extrañeza general que parece teñirlo todo: acciones, personajes, lugares y tiempo incluidos. En el testimonio de Gabrielle, hay un momento que deja entrever nítidamente este efecto:

Esa noche, contemplando a la madre y a la hija, tuve la extraña sensación de que las dos eran la misma y que una de ellas había inventado a la "otra" para hacernos creer que gozaba de alguna compañía. Digo esto y me parece estar aún en el mundo fantástico en el que se movía mi amiga (p. 129, las cursivas son mías).

En el testimonio de André, también se ejemplifica simultáneamente la descripción críptica a la que hacíamos referencia más arriba y lo ajeno que le resulta al narrador todo el universo de Mariana:

La dejé fumando y salí de la habitación sin haberla tocado y con la extraña sensación de que Mariana caminaba en la frontera de la luz y la sombra. Me sentí terriblemente oprimido, pensé que debería haberme quedado con ella y entrar abrazado a su cuerpo al extraño mundo por el que ella transitaba (p. 299, las cursivas son mías).

La irrealidad y las referencias a un mundo ajeno a éste se encuentran en los tres testimonios: Vicente se refiere a "personajes irreales" (p. 106); Gabrielle afirma que "las apariencias eran muy distintas a la realidad" (p. 137); André confiesa: "Me encerré en mi estudio a pensar en los mundos oscuros que pueden actuar en personajes aparentemente luminosos" (p. 324) y, más adelante, que "Mariana y a su hija, que repentinamente me parecieron irreales” (p. 327). El campo semántico de la extrañeza y la irrealidad permea la superficie de la prosa. Lejos

22 Winkler (p. 137) habla del abuso verbal y mental que Augusto ejerce sobre Mariana y enumera las etiquetas que usa para referirse públicamente a ella: "he publicly labels Mariana a liar $(128,289,291)$, a prostitute (90), an unfit mother (14, 153), a mental defective $(14,136,153)$, a racist $(200)$, and a vengeful ingrate who wants to ruin his career (200)". 
de tratarse de un puñado de selecciones léxicas aisladas, abundan por doquier, tiñendo la atmósfera de una incertidumbre sostenida que nunca se diluye ni se resuelve.

Tal como hemos señalado, existe una supuesta "verdad" referencial que Garro toma como punto de partida para la escritura de esta novela (y que muchas veces ha determinado la clave de interpretación a la hora de leerla). Es dentro del marco de la verosimilitud de la novela que la narración desafía, por medio del uso de los procedimientos de erosión, la fiabilidad de lo que se narra. Los términos en los que la verosimilitud misma está erigida a lo largo de la novela -es decir, la verosimilitud propia de esta obra y según la que se rige- se nutren de estos procedimientos con notable coherencia formal, prescindiendo deliberadamente de una relación de obediencia hacia los hechos referenciales.

\section{REENCUENTRO DE PERSONAJES}

En Reencuentro, el uso del maltrato como tema es más relevante que en Testimonios-incluso se vuelve una dominante-, y el efecto de extrañeza se presenta mucho más acentuado, tanto por esta hostilidad constante como por fuerza propia. Nos referiremos aquí a ambas cuestiones, no sólo porque se reiteran como un hilo conductor entre las obras, sino también porque a menudo se presentan íntimamente ligadas entre sí. Esta articulación imprime un sello particular a la incertidumbre esencial de estas novelas, que está cifrado en la violencia.

El maltrato hacia Verónica se cristaliza en la retahíla de insultos con la que Frank se dirige a ella. Entre ellos, encontramos: "mujer dudosa" (p. 37), "chiquita" (pp. 14, 37), "estúpida" (p. 30), "loca” (pp. 12, 39), "perra” (p. 42) y "puta” (pp. 22, 29, 106) 23. Asimismo, el maltrato se puede rastrear en las referencias explícitas al carácter de la relación, como se nota en ciertos sustantivos que se repiten y que tiñen semánticamente las páginas: “órdenes”, “degradación”, "humillación”, "desprecio", "ofensa", etcétera.

En el núcleo vital de esta novela se instala la extrañeza, deliberadamente subrayada y en diálogo con dos universos ficcionales por excelencia: el de las películas y el de las novelas. La esfera cinematográfica está evocada en la novela con gran insistencia. Desde el comienzo, se lee:

Cuando el auto entró en la carretera que bordeaba el Lago Mayor sintió que cruzaba una frontera, un límite invisible que le permitía verse como

${ }^{23}$ Esta enumeración es meramente a título ilustrativo; los insultos abundan y se repiten una infinidad de veces más de las que aquí se consignan. 
un personaje ajeno a ella misma. El mundo se volvió irreal como el de una película y su rostro se agrandó como el de una estrella de cine. Sintió alivio al saber que al final de esa noche aparecería la palabra fin. Lloró como en las películas (p. 7).

El cine aparece como elemento que hiende grietas en la linealidad del relato, por las que se abren otros planos de representación. En el ejemplo que sigue, lo único que "realmente" ocurre en el nivel más llano de la ficción es que Frank sale de la habitación y cierra la puerta; no obstante, la comparación con el cine ("como si saliera de una película”) permite introducir la escena, tal vez imaginada, de lo que Verónica "vio":

Vio salir a Frank de su habitación como si saliera de una película. Se vio a ella misma saliendo a una calle iluminada.

-¿Entendiste la película, Verónica? -le preguntaba alguien.

-No, no la entendí, pero era terrible... -contestaba ella, apresurando el paso en una acera llena de espectadores que se cerraban los cuellos de los abrigos y sacaban los llavines de sus automóviles. Verónica vio la puerta cerrada por Frank, en la que se escribía la palabra fin (p. 17).

Como se ve en el fragmento, el hiato se abre con la comparación y se cierra con el retorno a la imagen de la puerta cerrada; ella se ve a sí misma en este hiato, en un movimiento imperceptible hacia otra realidad, emparentada claramente con la dimensión de la pantalla de cine. Sin embargo, es en la misma novela donde se aclara la distancia que existe entre el cine, su estatuto y el desarrollo de la acción novelesca (la diferencia parte de la inscripción del cine dentro de la ficción):

Le parecía irreal que la gente acudiera a ver algo tan banal como una película. En el cinematógrafo los carretes de la película corrían en orden y las acciones se sucedían hasta desembocar en un final dichoso o desdichado; en cambio, su película se había quedado en una foto fija, en la que ella, Verónica, aparecía inmóvil sentada en el borde de una cama de resortes vencidos, esperando. ¿Qué esperaba? Lo ignoraba... "Debo provocar la palabra fin", se dijo, hundiendo la cabeza en la almohada olorosa a cabezas extrañas. Pero ningún gesto rompía el maleficio y ella no lograba reconocerse en la protagonista del principio del film. “CCómo terminan las historias de delincuentes?”, se preguntó una y otra vez tratando de recordar alguna que se ajustara al guión que alguien había escrito para ella; pero no encontró ningún final que se ajustara al desarrollo de la historia (pp. 241-242).

Al recurrir al séptimo arte y a esa irrealidad imaginada dentro de la propia ficción, se hace un giro inesperado a propósito del cine, pre- 
sente en el relato desde el primer momento. Una vez que como lectores hemos comprendido los matices, es Verónica (y no como hasta ese momento la voz narradora) la que se debate acerca de este dilema de los niveles de representación, como si se tratara de algo que pudiera estar a su alcance. Este recurso es crucial en la novela Tender is the night $(1934)^{24}$, de Francis Scott Fitzgerald, y funciona de un modo similar aquí al intentar borrar o confundir los límites de la ficción y la realidad; esta novela se cita profusamente en el final de Reencuentro, asunto sobre el que volveremos más adelante.

El extrañamiento también se hace evidente en el uso del lenguaje. Verónica parece alejarse de las palabras y contemplarlas con una percepción enrarecida, por lo menos en dos ocasiones. Primero se afirma que "la magnitud de la palabra asesino era tan aterradora que no quiso entender su contenido" (p. 23); más adelante que "la palabra [estúpida, que él le dice] le produjo un cansancio enorme, vivía en el desorden de la injuria" (p. 43). Este desapego esencial coopera con el resto de las estrategias que enumeramos.

Es notable en Reencuentro la manera en que se invita al diálogo con otras dos novelas, Tender is the night de Scott Fitzgerald (mencionado, por lo menos, en las pp. 213, 217, 218, 257) y Brideshead revisited de Evelyn Waugh (pp. 113, 159, 160, 218), tal como reiteradamente lo ha señalado la crítica. Amén de alguna otra comparación fugaz con otros personajes literarios (por ejemplo Alex "parecía un personaje escapado de una novela de Joseph Conrad”, p. 183), hay personajes de Reencuentro que, de acuerdo con sus propios relatos, ya han sido retratados, convertidos en personajes de ficción en el pasado, lo que, por cierto, esclarece la idea de "reencuentro" del título:

Nosotros hablaremos de lo nuestro "Ah, juventud divino tesoro, te vas para no volver, cuando quiero llorar no lloro y a veces lloro sin querer"... Rubén Darío. No está de moda, ¿y eso a mí que me importa? Tampoco

24 Las referencias al cine en Tender is the night son numerosas y variadas. Coinciden con la función que cumplen las referencias análogas en Reencuentro en las ocasiones en que se proponen hacer dudar a los personajes de la novela sobre la "realidad" en la que viven. Esto está presente desde el comienzo de la novela de Fitzgerald, donde leemos al comienzo del segundo capítulo:

«We thought maybe you were in the plot», said Mrs. Kisco. She was a shabby eyed, pretty young woman with a disheartening intensity. "We don't know who's in the plot and who isn't. One man my husband had been particularly nice to turned out to be a chief carácter-practically the assistant hero".

"The plot?" inquired Rosemary, half understanding. "Is there a plot?"

"My dear, we don't know", said Mrs. Abrams, with a convulsive, stout woman's chuckle. "«We're not in it. We're the gallery»" (p. 13).

Cabe señalar que Garro incluye este segmento en las extensas citas de la novela que incorpora en Reencuentro. 
está de moda Scott Fitzgerald... ¡Ah!, no pongas esa cara Frank. Yo le agradezco a Scott que nos haya incluido en esa magnífica novela. ¡Nos inmortalizó!... -¡Déjame hablar de quien me dé la gana! ¿Te da miedo aparecer en su novela? Pues yo estoy muy orgulloso, nos hizo un favor. Cuando nos hayamos muerto seguiremos vivos en ese libro. ¿Qué más puedes pedir si eres un mediocre? (p. 146).

Y, más adelante, el mismo Eddy reincide: "Yo me quedaré un rato para darle el gusto a esta niña; así podrá decir que conoció a dos personajes de Scott Fitzgerald" (p. 147). La idea de que los personajes de la novela (Reencuentro) se reconocen como tales y evocan, para ello, otras (Tendery Brideshead) dentro de la primera, produce una extraña cualidad de potenciación de la ficción enmarcada dentro de sí misma. Este efecto se profundiza por la inclusión de extensos fragmentos de ambas novelas en Reencuentro; de la novela de Fitzgerald se incrustan tres páginas completas (entre 256 y 259) y de la de Waugh, siete (261-267), con breves interrupciones. Además, los límites de las citas no siempre están marcados con claridad y por momentos las prosas de autores distintos se confunden ${ }^{25}$.

Las relaciones con ambas novelas son múltiples. En primer lugar, está la idea de que Frank, el protagonista hostigador de Reencuentro, fue el objeto de inspiración para dos personajes de Fitzgerald y Waugh. En el relato, se establece explícitamente la relación: "Evelyn Waugh lo situaba en Argentina a diferencia de Scott, que lo hacía aparecer chileno. Si estos dos escritores se habían ocupado de Frank, significaba que era un personaje fuera de lo normal" (p. 263). En el primero de los casos, se refiere a Anthony Blanche ${ }^{26}$ y, en el segundo, a Francisco, el hijo del chileno Señor Pardo y Ciudad Real. Por medio de esta operación, se atenta contra la condición ficcional de las obras y, al mismo tiempo, se cuestiona la supuesta "realidad" en la que viven los personajes en el relato. Por el hecho de haber usado personajes de la vida real

25 En la p. 260 la cita da paso, por medio de los puntos suspensivos, a un párrafo de Reencuentro, sin que medien las comillas de rigor. En este sentido, consigue el efecto de que haya incluso una escena en la playa, la escena inicial de Tender, que parece ser sitio de intersección con Reencuentro.

26 De acuerdo con la crítica especializada, el personaje de Anthony Blanche en Brideshead revisited está inspirado en el excéntrico poeta inglés Brian Howard (cf. Maurice Richardson, "Introduction”, en Brian Howard. Portrait of a failure, Anthony Blond, London, 1968, p. xii). Howard participó en la resistencia antifascista en España en la segunda mitad de la década de los años treinta (un poema suyo se incorporó en el número 6 de Les Poètes du monde défendent le Peuple Espagnol, plaquette que publicaba Nancy Cunard en París en 1936, y posteriormente se incluyó en el libro Poems for Spain, editado por Stephen Spender y John Lehmann, Portrait of a Failure, p. 374) y circulaba por Europa en las décadas siguientes, por lo que no puede descartarse la posibilidad de que Garro lo conociese u oyese historias sobre su escandalosa figura. Agradezco a Ernesto Montequin la orientación en éste y otros ámbitos. 
como objetos de inspiración, el efecto de confusión de la ficción con la realidad se extiende también hasta la recepción; tal como más tarde las obras de Garro serían objeto de lecturas biográficas simplistas, algo similar ocurrió con Tender is the night ${ }^{27}$ y un temor análogo puede intuirse en la nota del autor que precede a Brideshead revisited: "I am not I; thou art not he or she; they are not they. E.W.".

También hay vínculos con Tender is the night y Brideshead revisited en el nivel temático. En ambas novelas, hay parejas que en algún punto no funcionan y cuyos integrantes entablan relaciones extramatrimoniales (en la primera, la pareja central de Dick y Nicole Diver; en la segunda, el matrimonio de Charles Ryder y Celia y también el de Julia Flyte casada con Rex Mottram, así como la relación entre Charles y Julia). Las parejas disfuncionales o fracasadas están muy presentes en las novelas de Garro de la década de los ochenta ${ }^{28}$. En ambas novelas en inglés, además, se representa un mundo caótico en proceso de desintegración: Tender tiene lugar en la confusión de los años que siguieron a la Primera Guerra Mundial y Brideshead en la Segunda; de hecho, en el comienzo de la novela, el capitán Ryder narra desde la guerra misma. Los efectos de la guerra socavan todo tipo de certezas y dejan a los individuos en una intemperie vital que los desahucia; Reencuentro no está distante de esta atmósfera de falta de certezas ni a un mundo en proceso de desintegración.

Por último, así como Tender ofrece el tema del cine como estrategia para borrar o cuestionar los límites de lo real, Brideshead brinda un tono melancólico -y por momentos elegíaco- en virtud de la distancia que separa al narrador de los hechos narrados. Explícita o implícitamente, la memoria es crucial para Garro en el proceso de escritura de sus obras tardías. El segundo libro de Brideshead comienza con la frase: "My theme is memory, that winged host that soared about me one grey morning of war-time" (p. 225). En una operación que Garro remeda a la hora de publicar (y tal vez de escribir) estos tres libros que analizamos, Charles, el narrador de Brideshead, reconstruye sus vivencias de juventud en la primera parte de la novela, con notables digre-

27 Milton R. Stern afirma que: "Yet it also had suffered badly from ideologically distorting criticism and simplistic reading stemming from an overidentification of Fitzgerald's work with his life and times during the Jazz Age" "Tender is the night and American history", en The Cambridge companion to F. Scott Fitzgerald, ed. R. Prigozy, Cambridge University Press, Cambridge, 2002, p. 96). Asimismo, reconoce que el autor utilizó aspectos de su propia vida y de sus amigos para la creación de sus personajes.

28 "Luna de miel" es un cuento de Garro publicado en 1997 que comparte temas y atmósfera con Reencuentro de personajes y Testimonios sobre Mariana. En él, Eva y Vicente (nombres en los que resuenan los ecos de otros personajes de Garro) son amantes y están casados con otras personas. Este texto está incluido en El accidente y otros cuentos inéditos, Seix Barral, México, 1997. 
siones que insisten en la ubicación de la narración en un presente posterior a los hechos evocados ${ }^{29}$.

Quizá el extremo del procedimiento intertextual sea cuando en Reencuentro leemos que Verónica lee que en Brideshead se recitan pasajes de The waste land (p. 261). La lectura de Julie Jones de lo que describimos aquí es distinta y enriquece esta propuesta: "Garro's treatment of the Fitzgerald and the Waugh novels is parodic... She is not, however, interested in writing an extended parody of these works; instead, she uses them as points of departure for a different novel" ${ }^{30}$. Quizá esta novela diferente fue conseguida en virtud de algunos de los recursos que hemos descrito. En la referencia explícita de Verónica sobre los escritores, queda anotada una subrepticia acusación que parece volver el ojo sobre la autoridad que implica la autoría: “"Los escritores son fatídicos, ellos escribieron mi destino... No pidieron mi opinión», se dijo con lágrimas en los ojos" (p. 255). Los diálogos de la novela y sus personajes con el cine y la literatura se desvían por caminos impensados.

En la extrañeza y confusión que producen estos diálogos es en donde la novela se extingue. La propia condición -y existencia- de la protagonista se ve amenazada por la filtración de otros niveles de realidad: "Era presa de un carcelero invisible que paseaba por las páginas de dos novelas y por las calles de cualquier ciudad, mientras ella debía estar quieta y debía callar. ¿Por qué? Sabía que nunca iba a encontrar la respuesta... Se dio cuenta de algo que ya sabía: Verónica había dejado de existir" (pp. 268-269).

El final es, de este modo, tan incierto como el resto de la novela. En una vida primero castigada (en el nivel del relato) y luego astillada (desde su misma condición de personaje, al ser atravesada por otros niveles de realidad que amenazan su propia existencia), Verónica es víctima de algo que no sólo no comprende, sino que tampoco comprendemos los lectores que la contemplamos: la ambigüedad de este final abierto es tanto más sugerente cuando menos parece declarar su esencia. Eso que "ya sabía” no deja de ser algo inquietantemente incomprensible.

29 Varias de las digresiones incluidas en la primera parte (que evoca los recuerdos de juventud) tienen un tono elegíaco, además de melancólico, que sitúan al narrador en un presente que añora el pasado que se narra. Esto puede verse en las frases iniciales de dos de esas digresiones: "How ungenerously in later life we disclaim the virtuous moods of our youth, living in retrospect long, summer days of unreflecting dissipation, Desden figures of pastoral gaiety!" (p. 62); "The languor of Youth-how unique and quintessential it is! How quickly, how irrecoverably, lost!" (p. 79).

30 J. Jones, art. cit., p. 82. 
Tal como indicamos antes, Memorias es la reconstrucción de intención autobiográfica del viaje que el matrimonio Garro-Paz hace con motivo del "Segundo congreso internacional de escritores antifascistas" (el primero había tenido lugar en París dos años antes). Este congreso fue todo un acontecimiento intelectual dentro de un panorama político convulso como el europeo en el período de entreguerras, ya que contó con muchas figuras trascendentales de las letras, como Pablo Neruda, Alejo Carpentier, César Vallejo, André Malraux, Tristan Tzara y W.H. Auden, por mencionar sólo unos pocos ${ }^{31}$. Paz fue invitado como joven y promisorio poeta, autor de un poema titulado “¡No pasarán!”, posteriormente olvidado ${ }^{32}$. Es éste el contexto referencial que Garro se propone evocar en Memorias muchos años después. Si bien este texto se ha tomado como fuente de datos biográficos, es ineludible advertir el proceso de ficcionalización que los hechos y los recuerdos de esos hechos tuvieron antes de llegar a la obra. Los nombres propios de los personajes involucrados, algunos de los cuales veremos a continuación, provocan cierta ilusión de "realidad"; al mismo tiempo, la construcción de los personajes obedece al predominio de un punto de vista marcado que se manifiesta en los procedimientos que vamos a analizar. De los personajes construidos aquí, el más notable es el de Elena Garro por cómo el relato proyecta su imagen en primera persona.

Uno de los tópicos más frecuentes en Memorias es el de una ignorancia enunciada en primera persona, ilustrada de varias maneras. El libro se abre con esta breve y contundente frase: "Yo nunca había oído hablar de Karl Marx" (p. 21). Este íncipit comienza con el pronombre personal de la primera persona (muy repetido en todo el relato y resonante, casi estrepitoso, por su carácter prescindible desde un punto de vista gramatical), seguido de una predicación que ilustra su desconocimiento (sobre un personaje lo suficientemente conocido por sus lectores, aunque sólo sea de oídas, como para que la imagen sea provocativa). Esta ignorancia se asume en primera persona y se insiste en ella con abierta obstinación. El personaje afirma: "Yo, sin saber cómo ni por qué, iba a un Congreso de Intelectuales Antifascistas, aunque yo no era anti nada, ni intelectual tampoco, sólo era estudiante y coreógrafa universitaria" (p. 25); más adelante, insiste: "Yo no sabía, pero en España había habido una crisis política..." (p. 27). Hay también referencias laterales en la misma dirección, tales como "aunque yo ignoraba esas luchas" (p. 28) y "Yo no estaba politizada, de manera que igno-

31 Para información al respecto, véase Luis Mario Schneider, Segundo Congreso Internacional de escritores antifascistas (1937). T. 1: Inteligencia y Guerra Civil en España, Laia, Barcelona, 1978.

32 S. Messinger Cypess, op. cit., pp. 86-87. 
raba ese drama” (p. 31). En una especie de increscendo exasperado, más adelante, este "no saber" parece alcanzarlo todo: "Y la verdad es que yo no sabía nada" (p. 129). El punto culminante de esta serie es el que se extiende hasta el escamoteado presente del relato, pues no se oculta a los lectores que el acto de relatar tiene lugar muchos años después de los hechos narrados: "Me asomé a la ventana, no había tropas victoriosas, sólo un silencio tristísimo. Quise irme enseguida de España. «Me quiero ir a mi casa», le dije a Octavio Paz. Éste se indignó ante mi estupidez: «¡No sé por qué te traje!», dijo. Yo tampoco lo sabía, ni lo sé hasta el día de hoy" (p. 29, las cursivas son mías).

No obstante, en el mismo relato está el giro que revierte esta ignorancia en virtud de ser la primera persona la que enuncia, lo cual le permite parapetarse tras un atisbo de resistencia. Vemos este gesto en la siguiente frase: "La verdad es que no me interesaba comprender nada" (p. 67). Esta intención, expresada casi a modo confesional, provoca una especie de vuelta de tuerca a toda la iterada serie anterior, anclada en el verbo conjugado en presente. Tanta insistencia en la ignorancia, entonces, se vuelve sobre ella como algo proyectado, como veremos más adelante, desde afuera, por un mundo externo que la acosa, pero que nunca consigue superar la distancia que la separa de ella.

Esta iteración a propósito de la ignorancia se traduce, desde la actitud de la voz narradora, en la nulidad de su persona. Lo que parece constituir el extremo de su condición quizás esté alimentado por la compartida imagen de ignorancia que la refleja. Por lo menos, dos momentos ilustran nítidamente esta condición. El primero, cuando enumera los nombres de los viajeros mexicanos que van a España: "Se formaron dos grupos para ir a España: el de los invitados: Carlos Pellicer, Octavio Paz y José Mancisidor, y el de los espontáneos: Silvestre Revueltas, Juan de la Cabada, Fernando Gamboa, Chávez Morado y María Luisa Vera” (p. 24). Su ausencia en estas enumeraciones es más que elocuente. El segundo, que yuxtapuesto con éste puede leerse con un compartido sentido, es cuando ella se presenta con Acario Cotapos: “«¿Oye, tú quién eres?», me preguntó. «¡Nadie!», dije” (p. 30). Repitiendo la simulación de Ulises en Odisea, que Borges recupera en "Odisea, libro vigésimo tercero", Garro lidia con sus propios Polifemos. Muchas veces lo hace mediante el humor y revirtiendo las acusaciones que pesan sobre ella, por medio del énfasis y la abundancia, como veremos a continuación.

Las referencias que el resto de los personajes hacen de ella parecen mostrar esta misma imagen y, al mismo tiempo, contribuir a crearla. Las referencias a ella, si bien son varias, comparten como denominador común su pequeñez: Elenita, pequeña, chiquilla, niña, rubita, compañerita, camaradita. Asimismo, la acusan, en repetidas ocasiones, de "frivolidad" (p. 56), de "falta de gusto" (p. 48), de ser "mentirosa" (p. 61), de "inconsciencia" (id.), de "ignorancia política" (p. 164). De 
este pequeño catálogo, que tiene puntos en común con los catálogos análogos de las novelas, puede inferirse no sólo la reputación del personaje de Garro, sino también la existencia de un paisaje de humanos signados por costumbres gregarias. Con más ironía embiste sobre estas cuestiones en el siguiente fragmento:

Chávez Morado miró con mucha pena a Paz: "No te enojes, Octavio, ya sabes que no quiere entender", le dijo dándole palmaditas en la espalda. Los mexicanos siempre compadecieron a Paz por haberse casado conmigo. ¡Su elección fue fatídica! Me consuela saber que está vivo y goza de buena salud, reputación y gloria merecida, a pesar de su grave error de juventud (p. 61).

Por último, y para conectar con lo anterior, es de fundamental importancia señalar la percepción de ajenidad de Garro con respecto al entorno que la rodea. El cuidadoso proceso de construcción de esta distancia parece definir intrínsecamente al personaje, ya que éste no sólo se entiende únicamente con unos niños desconocidos -al referirse a "un grupo de chiquillos con mandiles a rayas", dice que "eran inteligentes y cautos y con los únicos que me había entendido. ¡Así de simple!” (p. 97), lo que alimenta, una vez más, su carácter de epítetos diminutos-, sino que enuncia la alteridad del universo que conforman las personas que la rodean:

Lástima que yo no pudiera salir corriendo para librarme de los discursos farragosos y de su voluntad de "martillo categórico" para imponer sus caprichos sobre los míos. Me daba cuenta de que con ellos yo había entrado en otro mundo. Pensaban al revés de cómo pensaba yo. "Todos cometeríamos el mismo error en las mismas circunstancias”, repetía mi padre. Nadie era condenable y Dios era el único que tenía poder para juzgarnos. En España todos éramos juzgables y cometíamos pecados ininteligibles. Y entre todos la más pecadora era yo por ser "pequeñoburguesa”. Ignoraba el significado de aquel estigma que había caído sobre mi cabeza frente a aquellos jueces que hablaban de "las contradicciones del capitalismo”. Esa frase me aturdía. Para mí ellos estaban llenos de contradicciones (p. 98, las cursivas son mías).

La construcción de la primera persona que narra se vale del procedimiento especular de refracción de las voces ajenas para situarse en un contexto social determinado. De manera análoga a como funcionaban los insultos de los que eran víctimas los personajes centrales de las novelas, el tejido de los dichos ajenos (como las palabras de Chávez Morado ya referidas, las de Rafael Alberti al sentenciar " "Esta chica, con esa vocecita sólo dice barbaridades»”, p. 23, o los apelativos como el de "pequeño-burguesa" que pesan sobre ella) está siempre puesto en cuestión y relativizado como tal. La interposición de otros en la nece- 
saria construcción de "Elena Garro" dentro de Memorias es un procedimiento que remeda, de algún modo, el uso desafiante del género testimonial en Testimonios y de las referencias a la hostilidad constante en Reencuentro.

\section{Comentarios finales}

La intersección entre Testimonios sobre Mariana, Reencuentro de personajes y Memorias de España 1937 puede trazarse desde varios lugares. El que elegimos aquí es el que se concentra en la conformación de las figuras centrales y, especialmente, en la elaboración de un universo extrano a su alrededor en virtud de las referencias que otros hacen de ellas. Es importante notar que, aunque se trate de textualidades distintas, ya desde su concepción, ya desde la modalidad de recepción que se condiciona desde las respectivas presentaciones (las dos primeras son novelas, mientras que la última es una obra deliberadamente autobiográfica, presentada como tal), usan procedimientos similares y obtienen efectos que apuntan en la misma dirección: la incertidumbre como resultado de un complejo trabajo literario, trabado exitosamente en distintos niveles articulados entre sí, como hemos ejemplificado a lo largo de este trabajo.

La falsa encrucijada de tener que escoger entre una ciega obediencia al afán documentalista (o vengador) de la literatura de Garro y una lectura que tomara los procedimientos como fuente de ambigüedad, equívoco e incertidumbre, se desarma al devolver a la ficción su condición de tal. Su riqueza está cifrada en la sostenida tensión, en la cual Garro logra resumir el complejo enigma de su escritura. Concentrando su labor escrituraria de las últimas décadas en el material biográfico (de indiscutible interés para sus lectores), despliega un intenso ejercicio literario que no se limita a la narración de la vivencia, sino que trabaja activamente sobre ella. Esta operación tiene una trascendencia ideológica doble; por un lado, la labor literaria sobre el material de su vida desdibuja los detalles anecdóticos hasta hacerlos irreconocibles, poniendo en cuestión el hecho mismo de usarlos como punto de partida; por otro, por medio de esta compleja operación se reafirma como escritora de ficción, valiéndose de la literatura -propia y ajena- para apartarse del rol de esposa de Paz con el que muchas veces fue etiquetada.

Como hemos visto, en Testimonios sobre Mariana, la construcción de tres niveles de evocación se combina con las crípticas descripciones, las fluctuantes, pero infranqueables distancias que separan a los narradores de Mariana, y con un campo semántico de la extrañeza; en Reencuentro de personajes, la hostilidad de la relación de Verónica con Frank está constituida por las referencias, tanto cinematográficas como 
novelescas, así como por un lenguaje desapegado y alienado; en Memorias de España 1937, la construcción de un yo narrador marcado por la ignorancia e impulsado a la propia anulación se articula con una compleja red de referencias de terceros y con la percepción del ser como algo ajeno o desubicado.

Estas estrategias, múltiples y variadas, funcionan en consonancia con un aspecto acerca del cual existe consenso crítico y variedad de lecturas: el trabajo de Elena Garro sobre el tiempo cronológico o histórico y su puesta en cuestión en la ficción ${ }^{33}$. En las obras analizadas, éste se vuelve un elemento más para apuntalar una estrategia corrosiva que invade todos los ámbitos; cuando Vicente augura que "hablar en un orden cronológico es difícil” (p. 11), además de introducirnos en la reconocible poética de Garro (por ejemplo, su trabajo sobre el tiempo en Los recuerdos del porvenir o "La culpa es de los Tlaxcaltecas"), prepara simultáneamente el terreno para un desmoronamiento inminente de algunas certezas.

Tal como hemos ilustrado con numerosos ejemplos, es evidente el trabajo de Elena Garro sobre el material con el que cuenta, también queda claro que la vaguedad de las referencias es parte de su objetivo $^{34}$. Este desplazamiento desde la nitidez hacia una especie de bruma,

33 Es en Los recuerdos del porvenir donde más se ha analizado la transfiguración del tiempo como procedimiento clave de construcción narrativa. MARTA PorTAL habla de un "tiempo doble (susceptible de otros desdoblamientos), alejado y simultáneo, anterior al año de 1927, y futuro, inlocalizable cronológicamente, situado en el porvenir" ("Elena Garro", en Proceso narrativo de la Revolución mexicana, Cultura Hispánica, Madrid, 1977, p. 223). Laura López Morales señala que: "La dimensión temporal será objeto de diferentes representaciones que suponen, de entrada, la ruptura del hilo cronológico y que se manifiestan ya sea en el reflejo especular de ciertas experiencias, ya en su reiteración cíclica, en la detención o sustracción del flujo temporal convencional" ("Las rupturas del tiempo", en Elena Garro. Recuerdo y porvenir de una escritura, eds. L.E. Gutiérrez de Velasco y G. Prado, p. 73). GLoria PRADO se refiere a un tiempo roto, embrujado y transformado en "fragmentos espejeantes, luces de prisma en movimiento" en su lectura de algunas piezas narrativas ("En el escenario del tiempo transmutado: la narrativa de Elena Garro", en Elena Garro. Reflexiones en torno a su obra, INBA, México, 1992, p. 49). Амy Kaminsky, en su inteligente lectura rastrea las posibles fuentes del tiempo de Los recuerdos del porvenir (Reading the body politic. Feminist criticism and Latin American women writers, University of Minnesota Press, Minneapolis-London, 1992, p. 77) y caracteriza un tiempo femenino (p. 81).

34 En una línea cercana, cabe tener presente que FrAnk DAUSTER ha examinado la confrontación de realidades que Garro pone en escena en sus obras de teatro y para ello enumera ilusiones, alucinaciones, sueños, sugerencias y evasiones como procedimientos que emplea iteradamente ("El teatro de Elena Garro: evasión e ilusión”, RevIb, 30, 1964, pp. 81-89). También en el ámbito de las obras teatrales de Garro, Octavio Rivera, por su parte, se concentra en la "irrealidad" que abunda en "Un hogar sólido" ("Un hogar sólido: realidad e irrealidad", en Elena Garro. Reflexiones en torno a su obra, pp. 55-62). Asimismo, esta perspectiva ya aparece en trabajos sobre Los recuerdos del porvenir, como cuando BALDERSTON explica que "there 
ambigua y extrañada, lejos de ser imperceptible está magnificado en las tres obras revisadas. La suma de estrategias y su combinada y simultánea articulación provocan un efecto de lectura descentrado y construyen, en el examen transversal de varias obras, un eje reconocible que vertebra una consolidada poética de la extrañeza y la incertidumbre. Reafirma así su muchas veces cuestionado estatuto de escritora por medio del pleno ejercicio del acto literario.

María Julia Rossi

University of Pittsburgh

is an oscillation between reality and fantasy, an ambivalence which is never resolved" ("The new historical novel: History and fantasy in Los recuerdos del porvenir", BHS, 46, 1989, p. 42). 
